\title{
Nano-Engineering of New Photoreactive Materials Having Fluorine Units: Synthesis and Photoalignment of Liquid Crystals
}

\author{
Rasha Ata Alaa ${ }^{1}$, Gurumurthy Hegde ${ }^{1,2^{*}}$, Arun M. Isloor ${ }^{3}$, Boodappa Chandrakantha ${ }^{4}$, \\ Shridhar Malladi ${ }^{3}$, M. M. Yusoff ${ }^{2}$, Lachezar Komitov ${ }^{1}$ \\ ${ }^{1}$ Department of Physics, University of Goteborg, Goteborg, Sweden; ${ }^{2}$ Faculty of Industrial Sciences and Technology, University \\ Malaysia Pahang, Gambang, Malaysia; ${ }^{3}$ Organic Chemistry Division, Department of Chemistry, National Institute of Technology \\ Karnataka, Mangalore, India; ${ }^{4}$ Syngene International Ltd., Bangalore, India. \\ Email: ${ }^{*}$ murthyhegde@gmail.com, isloor@yahoo.com,komitov@physics.gu.se
}

Received October $2^{\text {nd }}, 2012$; revised December $4^{\text {th }}, 2012$; accepted December $12^{\text {th }}, 2012$

\begin{abstract}
In order to investigate the photoalignment mechanism of nematic liquid crystals on an oxadiazoles, new 1,3,4-oxadiazole having fluorine atoms as terminal, as well as sideways was synthesized. Linearly polarized UV light shined in these nano-layered films causes the preferential direction of the liquid crystal molecules either perpendicular (in the case of terminal fluoro substitution) or parallel (in the case of sideways fluorine substitution) to the polarized direction. A powerful indication about the relationship between molecular structure and alignment properties where just by changing fluorine atom can change the entire alignment direction is proposed. Such information is indispensable for the design and synthesis of photoalignment materials for liquid crystal displays of high quality.
\end{abstract}

Keywords: Liquid Crystals; Fluorine; Parallel; Perpendicular; Irradiation

\section{Introduction}

Due to high molecular hyperpolarizabilities, elongated nature, chemically stable, sometimes with good electrontransport properties, many of the oxadiazole derivatives displays a number of interesting photo and nonlinear optical effects. Certain oxadiazoles can reveal liquid crystalline features and in particular, can show the elusive biaxial nematic phase. Theoretically proposed in 1970 by Freiser, the biaxiality can be observed in the nematic phase of boomerang-shaped oxadiazoles [1]. Oxadiazole rings can provide not only the lateral dipole from the oxygen and nitrogen atoms, but also the bent shape of the rigid cores. It is due to the polar substituents which are highly variable, and its attaching sites are also adjustable. Therefore, these benefits allow us to access a wide variety of mesophases simply by changing the polar moieties or their attaching positions [2]. Compounds with the 1,3,4-oxadiazole motif are generally chemically stable and have diverse luminescent properties, and are often emissive mesogens with good electron-transport properties [3] which seems to play an important role for the photoalignment properties of these materials. In general, the oxadiazoles are interesting for applications to elec-

"Corresponding author. troluminescent devices where they are the emissive materials [4].

On the other hand, for good electro-optical performances of liquid crystal displays (LCD), defect free and uniform liquid crystal (LC) alignments are required. Mechanical rubbing of thin polyimide alignment layers with cotton or nylon cloth is the most commonly used alignment method today to achieve uniform LC alignment because this method is highly reproducible and feasible in mass production of LCD $[5,6]$. However, conventional LCD employs the rubbing technique in order to obtain a uniform LC alignment exhibit asymmetric and narrow viewing angle characteristics and thus their applications to large-size and full color LCD are limited [7]. On the other hand, liquid crystal alignment by photoresponsive materials (nano scale thin photoresponsive solid films) has been studied as an alternative LC alignment method which is a promising technique for the fabrication of LCDs due to its noncontact nature and the possibility of producing a multidomain structure (photo-patterning) [8].

The photoalignment (PhA) effect of the thin films made from photoresponsive materials is due to photoinduced anisotropy of the surface physical properties of these films acting as an LC alignment layer. This surface 
anisotropy is generated due to the selective photoreactions of photoresponsive materials by linearly polarized UV light, for instance. The alignment films made from this kind of materials align the LC molecules along a preferential direction determined by the orientation of the light polarization, which in some cases is along the polarization direction or perpendicular to it. $\mathrm{PhA}$ effects of a variety of materials with different photosensitive groups mainly, azobenzenes [9], cinnamates [10], coumarin [11], maleimides [12] etc. were studied extensively during the past two decades [8]. Due to lack of suitable materials and good understanding of the $\mathrm{PhA}$ processes, the $\mathrm{PhA}$ is still hampered and not able to perform desired results which are demanding for industrial applications in the field of LCDs. Good understanding of the relations between molecular structure and $\mathrm{PhA}$ ability of the materials is necessary in order to design and synthesize proper materials for PhA of LCs. Furthermore, depending on the structure of the photoresponsive molecules, the illumination conditions with linear polarized UV light and many other processing parameters, the PhA films may promote orientation of the LC molecules either parallel or perpendicular to the polarization of the incident light with or without pretilt [13]. Owing to its high sensitivity, these kinds of orientation effects are also of great interest for application in nonlinear optics and optical storage devices [6]. It is worth to mention that thin film (typically between $20-100 \mathrm{~nm}$ ) made from photoresponsive materials are useful for many applications [14].

To gain knowledge about the relations between molecular structure and $\mathrm{PhA}$ ability, we designed and synthesized in this work heterocyclic compounds having 1,3,4oxadiazoles bearing 2-fluoro-4-methoxy phenyl moiety and studied their photo alignment properties. The experiments with alignment films prepared from the oxadiazole $4 \mathrm{~b}$ and oxadiazole $4 \mathrm{~d}$ reveal different $\mathrm{PhA}$ properties closely related to the position of fluorine in their structure.

\section{Experimental}

\subsection{Materials and Instrumentation}

All chemicals were purchased from Aldrich and used without further purification. Melting points were determined by open capillary method and were uncorrected. Elemental analysis was performed on Thermo Fin ningan FLASHEA $1112 \mathrm{CHN}$ analyzer. IR spectra (KBr pellets) were recorded on a Shimadzu FT-IR 157 spectrophotometer. ${ }^{1} \mathrm{H}-\mathrm{NMR}$ spectra were recorded on a BRUKER AMX $400 \mathrm{MHz}$ spectrometer using TMS as internal standard. Mass spectra were recorded on LCMS-Aglilent 1200 series with MSD using $0.1 \%$ aqueous TFA in acetonitrile system on C18-BDS column for $10 \mathrm{~min}$ duration. Ionization mode is EI for all the compounds.
The purity of the compounds was checked by TLC silica coated plates obtained from Merck. Figure 1 shows the scheme for the synthesis of oxadiazole molecules whereas Figure 2 shows the final products obtained from Figure 1 with different substitutions.

\subsection{Preparation of \\ Ethyl 2-fluoro-4-methoxybenzoate (2)}

To a mixture of 2-fluoro-4-methoxybenzoic acid (10 g, $0.0587 \mathrm{~mol})$ in ethanol $(100 \mathrm{ml})$ was added conc. sulphuric acid $(1 \mathrm{ml})$ and refluxed for $5 \mathrm{~h}$. The reaction mixture was concentrated, the solid separated was filtered, washed with water and recrystallised with ethanol to give 2 as white crystals. $(10 \mathrm{~g}, 85 \%) \mathrm{mp} .158^{\circ} \mathrm{C}$ $160^{\circ} \mathrm{C}$

\subsection{Preparation of Ethyl \\ 2-Fluoro-4-methoxybenzohydrazide (3)}

A mixture of ethyl 2-fluoro-4-methoxybenzoate (10 g, $0.0602 \mathrm{~mol})$ and hydrazine hydrate $(5.0 \mathrm{ml}, 0.1009 \mathrm{~mol})$ in ethanol $(100 \mathrm{ml})$ was heated under reflux for $8 \mathrm{~h}$. The reaction mixture was concentrated and left to cool. The solid product obtained was filtered, washed with water and recrystallised with ethanol to give 3 as colorless crystals. $(7 \mathrm{~g}, 74 \%) \mathrm{mp} .158^{\circ} \mathrm{C}-160^{\circ} \mathrm{C}$.

\subsection{General Procedure for Preparation of 2-(2-Fluoro-4-methoxyphenyl)- 5-substituted 1,3,4-oxadiazole (4)}

An equimolar mixture of acid hydrazide 3 with different aromatic carboxylic acid (a - e) was refluxed with phosphorous oxychloride $(10 \mathrm{vol})$ for $2-3 \mathrm{~h}$. The reaction mixture was concentrated through rotovapour, the residue was quenched with ice water and the solid separated was filtered off, washed with water and further purified by recrystallization with ethanol to afford 5 -substituted 1,3,4-oxadiazole bearing 2-fluoro-4-methoxy phenyl moiety as white solid [15].
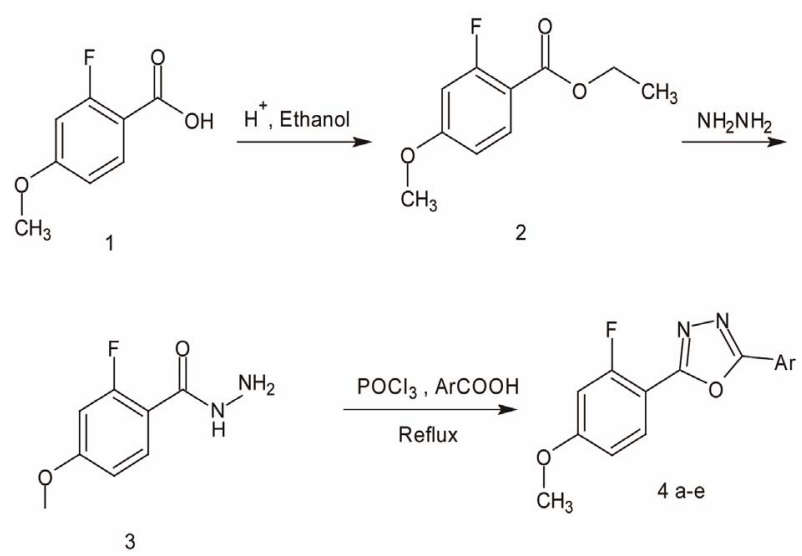

Figure 1. Scheme for Synthesis of new oxadiazoles. 

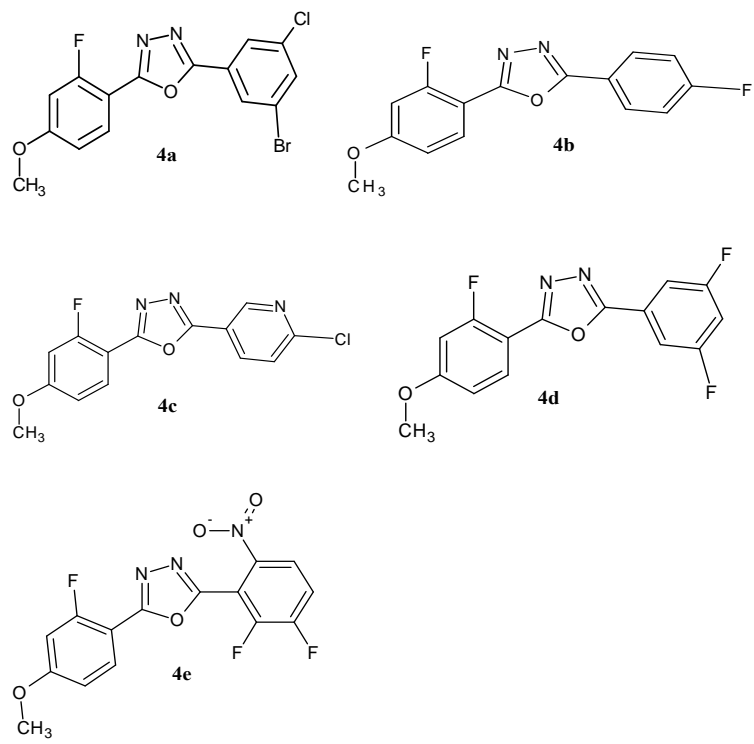

Figure 2. Chemical structures used in the present investigations.

\subsection{Preparation of 2-(2-Bromo-5-chlorophenyl)- 5-(2-fluoro-4-methoxyphenyl)- 1,3,4-oxadiazole (4a)}

To a mixture of 2-fluoro-4-methoxybenzohydrazide 3 (1 g, $0.0054 \mathrm{~mol})$ and 2-bromo-5-chloro benzoic acid (1.27 g, $0.0054 \mathrm{~mol})$ was added phosphorous oxychloride $(10$ $\mathrm{ml}$ ). The reaction mixture was refluxed at $100^{\circ} \mathrm{C}$ for $2 \mathrm{~h}$. The reaction mixture was cooled to room temperature, the excess of $\mathrm{POCl}_{3}$ was concentrated through high vacuum, the residue was quenched with ice and the solid separated was filtered and dried through a pump to afford the title compound $4 \mathrm{a}$ as a white solid. $(1.9 \mathrm{~g}, 90 \%) ; \mathrm{mp}$ $215^{\circ} \mathrm{C}-218^{\circ} \mathrm{C}$; IR $(\mathrm{KBr}) \mathrm{cm}^{-1} 3020(\mathrm{Ar} \mathrm{C}-\mathrm{H}), \mathrm{C}=\mathrm{N}$ (1625), C $\equiv \mathrm{C}(1540), \mathrm{C}-\mathrm{O}$ (1040, stretch of oxadiazole ring), C-F (1065); mass $\mathrm{m} / \mathrm{z}\left(\mathrm{M}^{+}\right)$382: ${ }^{1} \mathrm{H}$ NMR (400 MHz-DMSO-d ${ }_{6}$-ppm) $\delta 8.03-8.08$ (m, 1H, Ar-H), 8.00 $8.03(\mathrm{~d}, 1 \mathrm{H}, \mathrm{Ar}-\mathrm{H}, \mathrm{J}=7.8 \mathrm{~Hz}), 7.82-7.84(\mathrm{~d}, 1 \mathrm{H}, \mathrm{Ar}-\mathrm{H}$, $\mathrm{J}=7.0 \mathrm{~Hz}), 7.38-7.43(\mathrm{~m}, 1 \mathrm{H}, \mathrm{Ar}-\mathrm{H}), 7.12-7.18(\mathrm{dd}$, $1 \mathrm{H}, \mathrm{Ar}-\mathrm{H}, \mathrm{J}=2.4 \mathrm{~Hz}), 7.00-7.04(\mathrm{dd}, 1 \mathrm{H}, \mathrm{Ar}-\mathrm{H}, \mathrm{J}=$ $2.31 \mathrm{~Hz}), 3.88\left(\mathrm{~s}, 3 \mathrm{H},-\mathrm{OCH}_{3}\right)$. Anal. Found (calc.) for $\mathrm{Cl}_{5} \mathrm{H}_{9} \mathrm{BrClFN}_{2} \mathrm{O}_{2}$ (\%): C, 46.97 (47.0); H, $2.36(2.5) ; \mathrm{N}$, 7.30 (7.2).

\subsection{Preparation of 2-(4-Fluorophenyl)- 5-(2-fluoro-4-methoxyphenyl)- 1,3,4-oxadiazole (4b)}

To a mixture of 2-fluoro-4-methoxybenzohydrazide 3 (1 $\mathrm{g}, 0.0054 \mathrm{~mol})$ and 4-fluoro benzoic acid $(0.76 \mathrm{~g}, 0.0054$ mol) was added phosphorous oxychloride $(10 \mathrm{ml})$. The reaction mixture was refluxed at $100^{\circ} \mathrm{C}$ for $2 \mathrm{~h}$. The reaction mixture was cooled to room temperature, the excess of $\mathrm{POCl}_{3}$ was concentrated through high vacuum, the residue was quenched with ice and the solid separated was filtered and dried through a pump to afford the title compound $4 \mathrm{~b}$ as a white solid. $(1.4 \mathrm{~g}, 90 \%) ; \mathrm{mp} 210^{\circ} \mathrm{C}$ $212^{\circ} \mathrm{C}$; IR (KBr) cm ${ }^{-1} 3030(\mathrm{Ar} \mathrm{CH}), \mathrm{C}=\mathrm{N}$ (1635), $\mathrm{C} \equiv \mathrm{C}$ (1530), C-O (1030, stretch of oxadiazole ring), C-F (1060); mass m/z (M $\left.{ }^{+}\right)$289: ${ }^{1} \mathrm{H}$ NMR (300 MHz-DMSO $\mathrm{d}_{6}$-ppm). $\delta 8.07-8.16(\mathrm{~m}, 3 \mathrm{H}, \mathrm{Ar}-\mathrm{H}), 7.44-7.50(\mathrm{~m}, 2 \mathrm{H}$, Ar-H), 7.11 - 7.16 (dd, 1H, Ar-H, J = 2.4 Hz), 7.0 - 7.04 (dd, $1 \mathrm{H}, \mathrm{Ar}-\mathrm{H}, \mathrm{J}=2.4 \mathrm{~Hz}$ ), 3.87 (s, 3H, $-\mathrm{OCH}_{3}$ ). Anal. Found (calc.) for $\mathrm{C}_{15} \mathrm{H}_{10} \mathrm{~F}_{2} \mathrm{~N}_{2} \mathrm{O}_{2}(\%)$ : $\mathrm{C}, 61.65$ (61.3); $\mathrm{H}$, 3.66 (3.48); N, 9.72 (9.8).

\subsection{Preparation of 2-Chloro-5- [5-(2-fluoro-4-methoxyphenyl)-1,3,4- oxadiazol-2-yl] Pyridine (4c)}

To a mixture of 2-fluoro-4-methoxybenzohydrazide 3 (1 $\mathrm{g}, 0.0054 \mathrm{~mol})$ and 6-chloronicotinic acid $(0.84 \mathrm{~g}, 0.0054$ mol) was added phosphorous oxychloride $(10 \mathrm{ml})$. The reaction mixture was refluxed at $100^{\circ} \mathrm{C}$ for $2 \mathrm{~h}$. The reaction mixture was cooled to room temperature, the excess of $\mathrm{POCl}_{3}$ was concentrated through high vacuum, the residue was quenched with ice and the solid separated was filtered and dried through a pump to afford the title compound $4 \mathrm{c}$ as a white solid. $(1.5 \mathrm{~g}, 90 \%) ; \mathrm{mp} 224^{\circ} \mathrm{C}$ $235^{\circ} \mathrm{C}$; IR (KBr) cm 3030 (Ar C-H), $\mathrm{C}=\mathrm{N}$ (1625), C $\equiv$ C (1560), C-O (1080, stretch of oxadiazole ring), C-F (1040), C-Cl (833); mass m/z $\left(\mathrm{M}^{+}\right)$306: ${ }^{1} \mathrm{H}$ NMR (300 MHz-DMSO-d $\left.\mathrm{d}_{6}-\mathrm{ppm}\right) \delta 9.08-9.09(\mathrm{~d}, 1 \mathrm{H}, \mathrm{Ar}-\mathrm{H}, \mathrm{J}=2.4$ $\mathrm{Hz}), 8.47$ - 8.50 (dd, 1H, Ar-H, J = $1.98 \mathrm{~Hz}$ ), 8.07 - 8.13 (t, 1H, Ar-H, J = 8.61 Hz), $7.78-7.80(\mathrm{~d}, 1 \mathrm{H}, \mathrm{Ar}-\mathrm{H}, \mathrm{J}=$ $8.4 \mathrm{~Hz}), 7.12$ - 7.17 (dd, 1H, Ar-H, J = 11.2 Hz), 7.01 $7.05(\mathrm{dd}, 1 \mathrm{H}, \mathrm{Ar}-\mathrm{H}, \mathrm{J}=8.73 \mathrm{~Hz}), 3.88\left(\mathrm{~s}, 3 \mathrm{H},-\mathrm{OCH}_{3}\right)$. Anal. Found (calc.) for $\mathrm{C}_{14} \mathrm{H}_{9} \mathrm{ClFN}_{3} \mathrm{O}_{2}$ (\%): C, 55.61 (55.9); H, 3.17 (3.01); N, 13.35 (13.0).

\subsection{Preparation of 2-(3,5-Difluorophenyl)- 5-(2-fluoro-4-methoxyphenyl)- 1,3,4-oxadiazole (4d)}

To a mixture of 2-fluoro-4-methoxy benzohydrazide 3 ( 1 $\mathrm{g}, 0.0054 \mathrm{~mol})$ and 3,5 diflurobenzoic acid $(0.85 \mathrm{~g}$, $0.0054 \mathrm{~mol})$ was added phosphorous oxychloride $(10 \mathrm{ml})$. The reaction mixture was refluxed at $100^{\circ} \mathrm{C}$ for $2 \mathrm{~h}$. The reaction mixture was cooled to room temperature, the excess of $\mathrm{POCl}_{3}$ was concentrated through high vacuum, the residue was quenched with ice and the solid separated was filtered and dried through a pump to afford the title compound $4 \mathrm{~d}$ as a white solid. $(1.4 \mathrm{~g}, 87 \%) ; \mathrm{mp} 265^{\circ} \mathrm{C}$ $269^{\circ} \mathrm{C}$; IR (KBr) cm $3070(\mathrm{Ar} \mathrm{CH}), \mathrm{C}=\mathrm{N}(1675), \mathrm{C} \equiv \mathrm{C}$ (1576), C-O (1054, stretch of oxadiazole ring), C-F (1083); mass $\mathrm{m} / \mathrm{z}\left(\mathrm{M}^{+}\right)$307: ${ }^{1} \mathrm{H}$ NMR (300 MHz-DMSO-d $\left.{ }_{6}-\mathrm{ppm}\right)$ $\delta 8.10-8.16$ (t, 1H, Ar-H, J = 8.64 Hz), $7.78-7.81(\mathrm{~m}$, 2H, Ar-H), 7.57 - $7.64(\mathrm{~m}, 1 \mathrm{H}, \mathrm{Ar}-\mathrm{H}) 7.12-7.17(\mathrm{dd}, 1 \mathrm{H}$, Ar-H, J = 2.4 Hz), $7.01-7.05$ (dd, 1H, Ar-H, J = 2.52 Hz) $3.88\left(\mathrm{~s}, 3 \mathrm{H},-\mathrm{OCH}_{3}\right)$. Anal. found (calc.) for $\mathrm{C}_{15} \mathrm{H}_{9} \mathrm{~F}_{3} \mathrm{~N}_{2} \mathrm{O}_{2}$ 
(\%): C, 58.43 (58.8); H, 3.16 (2.96); N, 9.34 (9.2).

\subsection{Preparation of \\ 2-(2,3-Difluoro-6-nitrophenyl)- 5-(2-fluoro-4-methoxyphenyl)- 1,3,4-oxadiazole (4e)}

To a mixture of 2-fluoro-4-methoxybenzohydrazide 3 (1 g, $0.0054 \mathrm{~mol})$ and 5,6-difluoro-2-nitrobenzoic acid (1.1 g, $0.0054 \mathrm{~mol})$ was added phosphorous oxychloride (10 $\mathrm{ml}$ ). The reaction mixture was refluxed at $100^{\circ} \mathrm{C}$ for $2 \mathrm{~h}$. The reaction mixture was cooled to room temperature, the excess of $\mathrm{POCl}_{3}$ was concentrated through high vacuum, the residue was quenched with ice and the solid separated was filtered and dried through a pump to afford the title compound $4 \mathrm{e}$ as a white solid. (1.7 g, 89\%); mp $200^{\circ} \mathrm{C}-203^{\circ} \mathrm{C}$; IR (KBr) $\mathrm{cm}^{-1} 3040$ (Ar C-H), C=N (1645), $\mathrm{C} \equiv \mathrm{C}$ (1540), $\mathrm{C}-\mathrm{O}$ (1070, stretch of oxadiazole ring), C-F (1070); mass $\mathrm{m} / \mathrm{z}\left(\mathrm{M}^{+}\right) 352:{ }^{1} \mathrm{H}$ NMR (400MHz-DMSO d ${ }_{6}$-ppm). $\delta 8.59-8.63(\mathrm{dd}, 1 \mathrm{H}$, Ar- $\mathrm{H}, \mathrm{J}=$ $7.2 \mathrm{~Hz}), 8.33-8.38$ (dd, 1H, Ar-H, J = 7.2 Hz), 7.99 $8.04(\mathrm{t}, 1 \mathrm{H}, \mathrm{Ar}-\mathrm{H}, \mathrm{J}=7.6 \mathrm{~Hz}), 7.14-7.18(\mathrm{~d}, 1 \mathrm{H}, \mathrm{Ar}-\mathrm{H}, \mathrm{J}$ $=15 \mathrm{~Hz}), 7.039-7.07(\mathrm{dd}, 1 \mathrm{H}, \mathrm{Ar}-\mathrm{H}, \mathrm{J}=2.4 \mathrm{~Hz}), 3.88(\mathrm{~s}$, $3 \mathrm{H},-\mathrm{OCH}_{3}$ ). Anal. Found (calc.) for $\mathrm{C}_{15} \mathrm{H}_{8} \mathrm{~F}_{3} \mathrm{~N}_{3} \mathrm{O}_{4}(\%)$ : C, 51.44 (51.3); H, 2.56 (2.4); N, 11.46 (11.3).

\section{Preparation of Thin Solid Alignment Films}

Oxadiazole $(1 \% \mathrm{wt})$ was dissolved in tetrahydrofuran (THF) solvent and the solution was spin coated onto the surface of previously cleaned glass substrates for $10 \mathrm{se}-$ conds at $800 \mathrm{rpm}$ followed by 20 seconds at $2000 \mathrm{rpm}$. The oxadiazole films were baked for 15 minutes at $100^{\circ} \mathrm{C}$. This produces nano surfaces of 1,3,4-oxadiazole films (with thickness of about $50 \mathrm{~nm}$ ) on glass substrates. Experimental quartz substrates also were prepared in a similar way for light absorption study. The glass and quartz substrates covered with photoresponsive film were exposed to linearly polarized UV light using standard USHIO light exposure equipment equipped with deep medium pressure mercury lamp giving $3 \mathrm{~mW} / \mathrm{cm}^{2}$ linearly polarized UV light passing through polarizer and light filter cutting the light below $290 \mathrm{~nm}$. Conventional cells were prepared with the glass substrate after UV Light illumination with a cell gap of $3-4 \mu \mathrm{m}$. Nematic liquid crystal MLC $6873-100(\Delta \varepsilon>0)$ was filled at an isotropic phase in the cell via capillary action. The quality of PhA was determined by polarizing optical microscope with crossed polarizers. The direction of the preferred alignment of the liquid crystal molecules was found using the birefringence compensation method.

\section{Results and Discussion}

The formation of oxadiazole 4 was confirmed by re- cording its IR, NMR \& mass spectra. IR spectrum of oxadiazole showed the Ar- $\mathrm{H}$ band at $3097 \mathrm{~cm}^{-1}, \mathrm{C}=\mathrm{N}$ band at $1594 \mathrm{~cm}^{-1}, \mathrm{C}=\mathrm{C}$ band at $1560 \mathrm{~cm}^{-1}$, and $\mathrm{C}-\mathrm{F}$ band at $1093 \mathrm{~cm}^{-1}$. The stretch of oxadiazole ring appeared at $1057 \mathrm{~cm}^{-1}$ due to C-O. Mass spectrum of $4 \mathrm{a}$ showed molecular ion peak $\mathrm{m} / \mathrm{z}\left(\mathrm{M}^{+}\right)$364. ${ }^{1} \mathrm{H}-\mathrm{NMR}$ spectrum showed multiplet in the region of $\delta, 7.00$ to 8.07. A singlet appearing at $\delta, 2.73$ is due to three protons of $-\mathrm{OCH}_{3}$. Similarly other molecules showed their characteristic peaks [15].

Table 1 summarizes the results obtained using different substitutions. It is evident from the table that the alignment films made from the compound $4 \mathrm{a}$ and $4 \mathrm{c}$, with the substitution of $\mathrm{Cl}$ and $\mathrm{Br}$ unable to promote alignment of the nematic liquid crystal.

On the other hand, the compound $4 \mathrm{~b}$, where fluorine is attached to the end of the molecule and $4 \mathrm{~d}$, where fluorine is attached to the both sides of the molecule, was found to produce high quality alignment whereas $4 \mathrm{e}$, with the substitution of two fluorine groups on the same side promoted week PhA. Therefore, only the experimental results related to compounds $4 \mathrm{~b}$ and $4 \mathrm{~d}$ will be discussed here.

$\mathrm{UV}$-vis spectroscopy data of $4 \mathrm{~b}$ and $4 \mathrm{~d}$ presented in Figure 3, when fluorine is attached to the end of the molecule (in the case of $4 \mathrm{~b}$ ) and fluorine attaches to the both sides of the molecule (in the case of $4 \mathrm{~d}$ ), showed two peaks, one at $260 \mathrm{~nm}$, and the other at $\sim 330 \mathrm{~nm}$. Since peak at $260 \mathrm{~nm}$ is non-photoactive, is eliminated by placing $290 \mathrm{~nm}$ long pass filter. For the compound comprising of fluorine attached at the end of the molecule (4b), was found to promote liquid crystal planar alignment with preferred direction perpendicular to the light polarization direction. Whereas for the compound comprising of fluorine attached to the both sides of the molecules (4d), was found to promote liquid crystal planar alignment with preferred direction parallel to the light polarization direction. The quality of the photo alignment was uniform in both cases (see Figure 4).

Hence, we may conclude that the position of fluorine plays very vital role in the structure making the liquid crystal molecules to change their direction. This result is

Table 1. Photoalignment effeets and molecular orientation based on the substitution of $\mathrm{F}, \mathrm{Cl}$ and $\mathrm{Br}$.

\begin{tabular}{cccc}
\hline $\begin{array}{c}\text { Materials } \\
\text { used in } \\
\text { this study }\end{array}$ & $\begin{array}{c}\text { Duration of } \\
\text { UV exposure } \\
\text { (min) }\end{array}$ & $\begin{array}{c}\text { Photoalignment } \\
\text { results }\end{array}$ & $\begin{array}{c}\text { Molecular } \\
\text { orientation }\end{array}$ \\
\hline $4 \mathrm{a}$ & 15 & No alignment & No alignment \\
$4 \mathrm{~b}$ & 15 & Good & Perpendicular \\
$4 \mathrm{c}$ & 15 & No alignment & No alignment \\
$4 \mathrm{~d}$ & 15 & Good & Parallel \\
$4 \mathrm{e}$ & 15 & Weak & Perpendicular \\
\hline
\end{tabular}



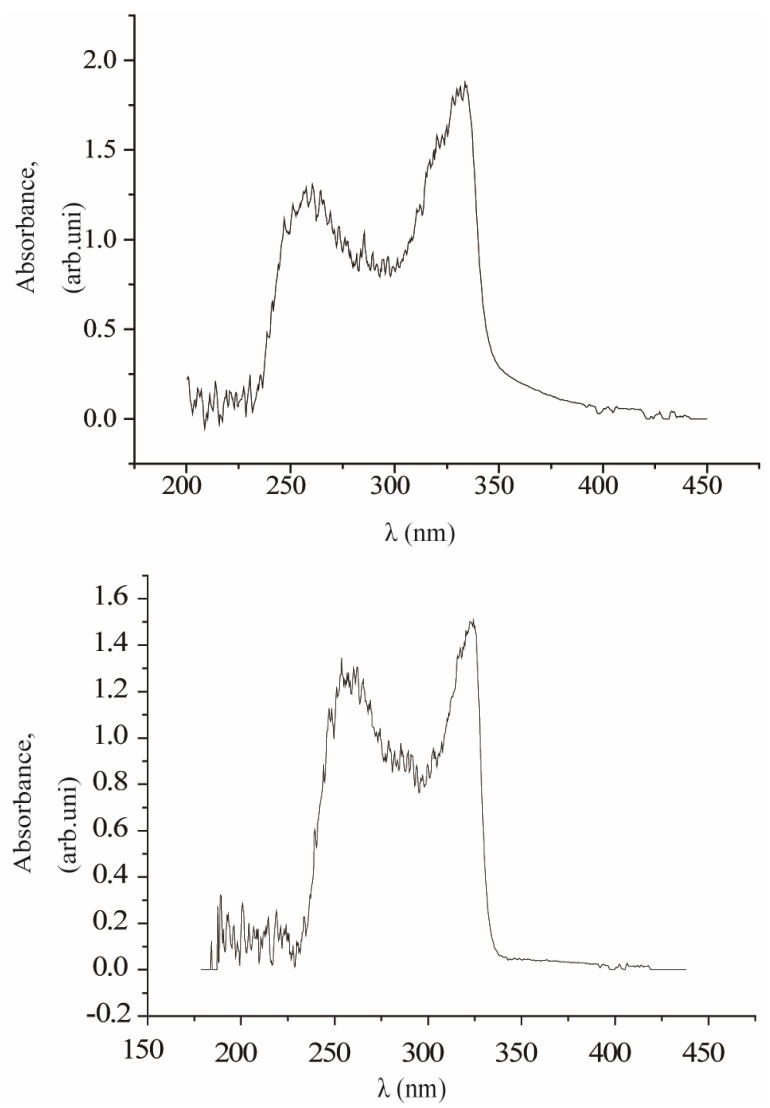

Figure 3. UV/vis absorption spectra of the compound $4 b$ (top), 4d (bottom) before illumination. Peak absorbance is around $330 \mathrm{~nm}$. Worthwhile to mention that, after illumination, $4 \mathrm{~b}$ aligns perpendicular and $4 \mathrm{~d}$ aligns parallel to the light polarization direction.

very powerful since it helps to design and synthesis of PhA materials of high quality and also controllable polarization directions.

By adding polymer groups in the molecule or by increasing the anisotropy in the structure can increase the stability. As of now present alignment won't stay for long time if we bake the material for a long time. Careful investigations is necessary to improve the stability of the aligning layer.

At wavelength i.e., $\sim 330 \mathrm{~nm}$, the absorption wavelength of $4 \mathrm{~b}$ and $4 \mathrm{~d}$ compound, the intensity of the medium pressure mercury lamp is low, so it takes much longer time to obtain PhA with this kind of oxadiazoles. However, by using a suitable UV light source, one will be able to get very fast PhA effect using ozadiazoles. On the other hand, one can also increase/decrease the light absorption wavelength of the ozadiazole molecules (say around 313 or $365 \mathrm{~nm}$ where UV light source has strong picks) by a proper molecular design which decreases the duration of illumination.

With subsequent ozone treatment of the substrates before spin coating with the solution containing the $\mathrm{PhA}$

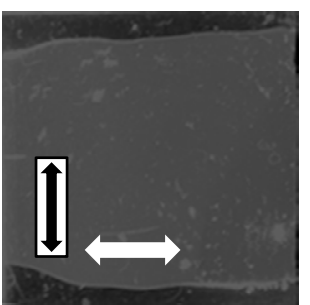

(a)

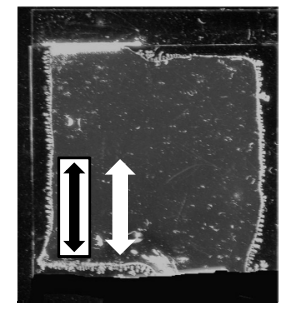

(c)

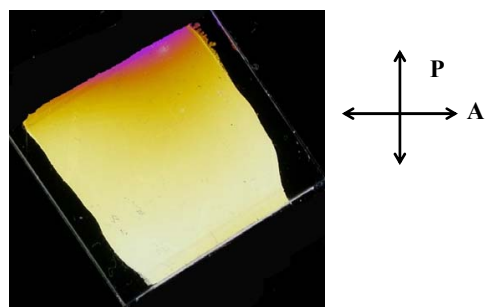

(b)

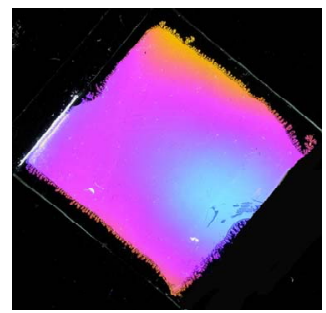

(d)
Figure 4. Photographs of the cells containing alignment layer made from the compound $4 b$ (a and b) and $4 d$ (c and d), respectively, inserted in between two crossed polarizers. The UV light polarization direction is indicated by a black arrow whereas the alignment direction of the liquid crystal in the cells is represented by the white arrow. The dark cell image corresponds to its position between crossed polarizers with the cell optic axis oriented along one of the polarizers whereas the bright image is taken after rotating the cell at $45^{\circ}$. The liquid crystal alignment in the cells is perpendicular, for $4 \mathrm{~b}$, and parallel, for $4 \mathrm{~d}$, to the light polarization direction exhibiting in both cases excellent quality.

material, improved the quality of alignment promoted by these two compounds drastically.

Let us discuss about the cause of this surprising phenomena. It is reported in the literature that thiophene undergo reorientation upon light illumination [16]. Likewise thiophenes, the polarized UV light drives the molecule of $4 \mathrm{~b}$ compound to position perpendicular to the light polarization direction since the fluorine is attached laterally to the end of the molecule. This orientation of the molecules of $4 \mathrm{~b}$ probably corresponds to the minimum molecular excitation by the UV light. For the same reason the molecules of $4 \mathrm{~d}$ compound, where the position of the fluorine atoms in the structure of $4 \mathrm{~d}$ is changed $90^{\circ}$ with respect to the molecular long axis, orient their molecular axis perpendicular to the light polarization direction. Because of the competing effects of two fluorine atoms, it might be not possible for the entire molecule to change their direction rather they exhibit parallel orientation.

\section{Conclusion}

We have synthesized new 1,3,4-oxadiazole derivatives, which have been characterized by IR, NMR, mass spectral data and also by $\mathrm{C}, \mathrm{H}, \mathrm{N}$ analyses. Our investigations showed that the molecular structure of the materials possessing PhA ability is of vital importance for the charac- 
teristics of the alignment promoted by them. In particular, the position of fluoro substitution in the molecular structure of these materials is important for obtaining $\mathrm{PhA}$ of high quality (excellent dark state) with good thermal stability. This study also suggests that the oxadiazoles can successfully be used as PhA materials. Further studies concerning the aligning behaviour are in progress and will be reported soon.

\section{Acknowledgements}

GH is thankful to the Ministry of Higher Education Malaysia for financial support in the form of ERGS grant RDU120602. AMI is thankful to the Department of Atomic Energy, Board for Research in Nuclear Sciences, Government of India for "Young Scientist" award.

\section{REFERENCES}

[1] L. A. Masden, T. J. Dingemans, M. Nakata and E. T. Samulski, "Thermotropic Biaxial Nematic Liquid Crystals," Physical Review Letters, Vol. 92, 2004, pp. 145505145508. doi:10.1103/PhysRevLett.92.145505

[2] M. Grel, D. D. C. Bradley, M. Inbasekaran and E. P. Woo, "A Glass-Forming Conjugated Main-Chain Liquid Crystal Polymer for Polarized Electroluminescence Applications," Advanced Materials, Vol. 9, No. 10, 1997, pp. 798-802. doi:10.1002/adma.19970091006

[3] C. Adachi, S. Tokito, T. Tsutsui and S. Saito, "Organic Electroluminescent Device with a Three-Layer Structure," Japanese Journal of Applied Physics, Vol. 27, No. 4, 1988, pp. L713-L715. doi:10.1143/JJAP.27.L713

[4] J. Han, S. S.-Y. Chui and C.-M. Che, "Thermotropic Liquid Crystals Based on Extended 2,5-Disubstituted-1,3,4oxadiazoles: Structure-Property Relationships, VariableTemperature Powder X-Ray Diffraction, and Small-Angle X-Ray Scattering Studies," Chemistry Asian Journal, Vol. 1, No. 6, 2006, pp. 814-825. doi:10.1002/asia.200600252

[5] S. Kobayashi and Y. Iimura, "Surface Liquid Crystal Molecular Alignment in LCDs and Their Electro-Optical Performance," SPIE Proceedings, SPIE Photonics, Vol. 2175, 1994, p. 122.

[6] V. G. Chigrinov, M. Kozenkov and H. S. Kwok, "Photoalignment of Liquid Crystalline Materials: Physics and Applications," Wiley Publication, Chichester, 2008.

[7] K. W. Lee, A. Lien, J. H. Stathis and S. H. Paek, "Control and Modification of Nematic Liquid Crystal Pretilt Angles on Polyimides," Japanese Journal of Applied Physics, Vol. 36, 1997, pp. 3591-3597.
doi:10.1143/JJAP.36.3591

[8] O. Yaroshchuk and Y Reznikov, "Photoalignment of Liquid Crystals: Basics and Current Trends," Journal of Materials Chemistry, Vol. 12, No. 2, 2012, pp. 286-300. doi:10.1039/c1jm13485j

[9] O. Yaroshchuk, H. Gurumurthy, V. G. Chigrinov, H. S. Kwok, H. Hasebe and H. Takatsu, "Photoalignment Properties of Brilliant Yellow Dye," International Display Workshop, Sapporo, 5-7 December 2007, p. 1665.

[10] M. Schadt, K. Schmitt, V. Koznikov and V. Chigrinov, "Surface-Induced Parallel Alignment of Liquid Crystals by Linearly Polymerized Photopolymers," Japanese Journal of Applied Physics, Vol. 31, 1992, pp. 2155-2164. doi:10.1143/JJAP.31.2155

[11] M. Schadt, H. Seiberle and A. Schuster, "Optical Patterning of Multi-Domain Liquid-Crystal Displays with Wide Viewing Angles," Nature, Vol. 381, No. 6579, 1996, pp. 212-215. doi:10.1038/381212a0

[12] L. O. Vretik, V. G. Syromyatnikov, V. V. Zagniy, E. A. Savchuk and O. Yaroshchuk, "Problem of Photoalignment in the LCD's Development: Synthetic Routes in Its Solving," Molecular Crystals and Liquid Crystals, Vol. 486, No. 1, 2008, pp. 57-65. doi: $10.1080 / 15421400801917395$

[13] S. Sato, H. Ito, T. Mizunuma, K. Nagai, H. Matsumoto and S. Matsumoto, "Substitute Effect of Fluorine-Containing Polyimides with Hexafluoroisopropylidine Group on Photoalignment of Liquid Crystal Molecule," Journal of Photopolymer Science and Technology, Vol. 24, No. 6, 2011, pp. 617-623. doi:10.2494/photopolymer.24.617

[14] S. G. Hahm, S. W. Lee, T. J. Lee, S. A. Cho, B. Chae, Y. M. Jung, S. B. Kim and M. Ree, "UV-Driven Switching of Chain Orientation and Liquid Crystal Alignment in Nanoscale Thin Films of a Novel Polyimide Bearing Stilbene Moieties in the Backbone," The Journal of Physical Chemistry B, Vol. 112, No. 16, 2008, pp. 4900-4912. doi:10.1021/jp7101868

[15] B. Chandrakantha, P. Shetty, V. Nambiyar, N. Isloor and A. M. Isloor, "Synthesis, Characterization and Biological Activity of Some New 1,3,4-Oxadiazole bearing 2-Fluoro4-Methoxy Phenyl Moiety," European Journal of Medicinal Chemistry, Vol. 45, No. 3, 2010, pp. 1206-1210. doi:10.1016/j.ejmech.2009.11.046

[16] H. Zhang, S. Shiino, A. Shishido and T. Ikeda, "A Thiophene Liquid Crystal as a Novel $\pi$-Conjugated Dye for Photo-Manipulation of Molecular Alignment," Advanced Materials, Vol. 12, No. 18, 2000, pp. 1336-1339. doi:10.1002/1521-4095(200009)12:18<1336::AID-ADM A1336>3.0.CO;2-A 